\title{
Usage and Usefulness of Social Media IN EVERYDAY-LIFE INFORMATION SEEKING AMONG INTERNATIONAL STUDENTS
}

\author{
Mu Yu \\ University of Malaya \\ mymargaret@163.com \\ Siti Ezaleila Mustafa \\ University of Malaya \\ ezaleila@um.edu.my
}

\begin{abstract}
In recent years, the number of students studying abroad has been increasing rapidly. However, adapting to life in different countries, particularly in Malaysia which is a multi-cultural country, is difficult and students are faced with a variety of challenges. As such, they may need more information for their cultural adaptation or daily life use from diverse channels or sources. By conducting focus group discussions, this study focuses on examining the use of social media and its usefulness in everydaylife information seeking (ELIS) among international students at the University of Malaya. Focus group discussions among graduate students suggested that social media ELIS centre around information about home and families, academic matters and news/current affairs. On the other hand, new/current affairs, self-improvement and information about friends for socialization emerged as key in their ELIS on social media. What is apparent, however, is that international students view the information acquired via social media is useful for the fulfilment of their everydaylife needs.
\end{abstract}

Keywords: social networking site, online communication, information seeking, new media, uses and gratifications, Malaysia

\section{INTRODUCTION}

As the economy develops and the conception of education changes, more and more students choose to study or are sent to study in other countries. With a different background from the host country and other people in the host country, all international students encounter various difficulties in acculturative adjustment, challenges in adapting to the environment of the host country, and certainly a strong sense of homesickness as well. To help them acculturate to life in Malaysia, it is useful for international students to learn about the host country's culture. This will help them to find balance between their home culture and that 
of the host country. In addition, access to the latest news or information about their home countries and families also helps during their adjustment to living and studying in the new environment. Therefore, gratifying the need for information seeking is essential, as it helps to secure a sense of belonging (Williamson \& Roberts, 2010) and ensure a smoother and easier cross-cultural transition (Shoham \& Strauss, 2008).

Generally, students, as do others, acquire everyday-life information through a wide range of sources, channels and platforms. However, such everyday-life information is difficult to find through campus resources alone (Given, 2002). If compared with traditional media forms, which are typically restricted to the place of performance and limited in reach, social media is more robust as it serves to connect people across time zones and geographical boundaries via online common platforms, and are able to connect users who have the same interests or questions to share their lessons, opinions or experience by gathering and exchanging information, and giving feedback. The trend of utilizing this new media among students seems to be increasing daily, particularly among the students at higher levels of education (Madden \& Jones, 2002; Jones et al. 2009; Zickuhr, 2010). As for international students living and studying overseas, through this platform, they can acquire or share certain information needed from others to help them solve the problems they face and find a psychological sense of dependence and belonging which could help them easily adjust to the new environment and culture.

Based on UNESCO statistic, Malaysia is among top 20 countries for international students with the average ratio of 1:10, one of the highest proportions of international versus domestic students in the academic world. In 2014, Malaysia had 135,502 international students from about 160 nations, studying in public and private higher education institutions as well as international schools (The Sun Daily, 29 January 2015). Based on Malaysian Higher Education Ministry, 74996 international students studying in private tertiary institutions, an increase of $29.9 \%$ from 2013 while in the public institutions, the number was 32,842. Most of them come from the Middle East, Southeast Asia, East Asia, and African countries, and a small number from Europe.

For Zuria et al (2010), the international students living and studying in Malaysia face more challenges with regard to culture and climate. Furthermore, due to Malaysia being a multi-cultural and multi-ethnic country. Therefore, it can be assumed that international students in Malaysia may need a greater variety of information for their cultural adjustment, which includes adjusting to the food, the language, local religious habits, as well as adjusting to the climate and accessing information, current affairs, and news every day. People can acquire information through a wide range of sources, channels and platforms. However, such everyday-life information is difficult to find through campus resources alone (Given, 2002). Furthermore, compared to conventional media, the trend of utilizing social media among students seems to be increasing daily, particularly among the students at a higher level of education.

\section{LITERATURE REVIEW}

Malaysia's unique environment means that Islam and Southeast Asian traditions exert powerful influences on local society and culture (Zuria et al., 2010), sometimes the gap between the students' culture and the new culture increases the likelihood of intrapersonal 
and interpersonal conflicts. Some researchers suggest that international students learn as much as possible about the new culture they are moving to (Lin \& Yi, 1997). For example, Zuria et al (2010) discovered that learning phrases from the new language helps students communicate with locals in their host country, contributing to a better understanding of local customs, and easing their efforts to settle in. Notably, other researchers have found that a lack of communication and interaction with local people may exacerbate cultural shock and communication difficulties (Chen, 1999).

International students typically face challenges in adapting to the new environment. Ward, Leong and Kennedy (1998) proposed that there are two facets of cross-cultural adaptation; namely psychological and socio-cultural. The first one is concerned with the internal sense of well-being and how students cope with stress. The second one refers to the students' ability to integrate into their new culture and learn about it (Ward et al., 1998). Besides that, when moving to a new country, one of the most stressful issues for new students is homesickness. Most students experience a feeling of loneliness and loss due to separation from their families, friends and communities (Lui, 2009; Sandhu, 1994). In addition, they may even miss relatively normal day-to-day things like their national cuisine (Lin \& Yi, 1997; Lui, 2009). During such a phase, students need to stay in contact with their families and rely on the long-distance support of their families to help them cope with the new environment (Cox et al, 2005).

Regarding information seeking, studies by Warner, Murray and Palmour (1973) indicate that normal people experience around 9000 questions or problems faced by residents in everyday contexts. The main categories of these questions are academic, transportation, shopping, medical matters, jobs and entertainment, as well as finances and legal matters. Thus, for students who experience problems adapting to a new culture (Lin \& Yi, 1997; Poyrazli \& Grahame, 2007; Smith \& Khawaja, 2011; Tseng \& Newton, 2002; Ward et al., 2001), some studies examined how important it is to deal with such difficulties when adapting to a new environment (Bauer et al, 2007). It is very important for students to find relevant information to help them cope with the challenges they have experienced and resolve these issues with the help of information gleaned from their search.

There are three key factors that may influence information seeking behaviour among international students: information needed, the environment and the seeker (personal factors) (Marchionini, 1997). In a new environment, students have a great need to find information that is useful for their daily lives. For example, Korean students in the US usually search for news of their home country online to cope with their homesickness (Jeong, 2004). This is common behaviour among international students. As for the current study on everyday-life information seeking (ELIS) needs of international students, it is noteworthy that students also consider school and university to be essential to their social lives (Agosto \& Hughes-Hassell, 2005; Given, 2002). This indicates that students primarily focus on seeking information for academic work. Therefore, it is possible to define the ELIS of international students' as the seeking and acquisition of various types of information that they use to help them adjust to their new environment and tackle their daily problems in school and otherwise.

Studies regarding the difficulties faced by international students in Malaysia has been conducted by Masoumeh and Syed (2001) and Zuria et al (2010) that found students had the most difficulty with social and recreational issues, difficulties with curriculum and teaching methods, followed by troubles related to their future careers, problems adjusting to academic 
workloads and finally financial, lifestyle and career related problems. Meanwhile, Zuria et al (2010) found that international students experienced three main adaptation issues, namely culture and values, food, language and sanitation practices of Malaysian society; Malaysia's humid climate; and lack of support services or facilities.

Among students, social media help them find out more about their friends' news because social media are free of charge and accessible (Garrett \& Cutting 2012; Talug 2012). Results of Lin's study (2002) found that the advent of social media is improving communication and helping people connect together. Lon S. Cohen (in Zickuhr, 2010) stated that "social media can be called a strategy and an outlet for broadcasting, while social networking is a tool and a utility for connecting with others". Armstrong and Franklin (2008) said that "social media have audio and visual capabilities consisting of web-blogs, wikis, social bookmarking, media sharing spaces, RSS Feeds, micro-blogging sites, MySpace, Facebook, LinkedIn has capabilities to promote synchronous or asynchronous interactions and communication". Generally, social media is computer-based technology that facilitates the sharing of ideas, thoughts, and information through the building of virtual networks and communities. Thus, this new media have the ability to improve regular communication channels.

Pettigrew et al (2002) demonstrated that social media can influence online activities, and changes the way people search and obtain information. Another study examined the information seeking habits of Korean graduate students in U.S., and the findings show that Korean students rarely read local or national newspapers and few watch television (Jeong, 2004). Using social media can help international students adapt faster to the new country based on their environmental conditions, sociological factors, and psychological dispositions. social media helps facilitate adaptation and connecting with their new country and their home country. One study examined the social networking sites (SNS) types that fulfil international students' ELIS in U.S. and results indicated that the main information categories for daily life were finance, health, news of the home country, housing and entertainment (Sin \& Kim, 2013). This shows SNS are beneficial and the most frequently used social media among international students. However, only SNS were examined, not other social media.

The popularity of social media has significantly altered daily life for many people. An ever larger number of users rely on social media for news, web searches, and entertainment or simply for spending time (Giannakos et al., 2012). Social media has provided people with convenient and rapid access to a wealth of useful information, such as breaking news, e-commerce, online shopping, references, or constructing and preserving their social circles, to health information, travel information (Whiting \& Williams, 2013).

Social media are interactive; thus they facilitate the free exchange of information and active discussions among users. For instance, Twitter encourages users to engage with one another for entertainment and private expression, checking public opinion, and seeking and distributing information (Hwang \& Shim, 2010; Java et al, 2007; Mischaud, 2007; Zhao \& Rosson, 2009). This new media even plays a role in encouraging people to become involved in politics. Users frequently forward and share political news stories with friends, and often express their support for political candidates or parties through social media comments and posts (Park, 2013). According to Maqsood (2008) who surveyed information-seeking among Pakistani students and use of social networks during political crises, social media play an important role among Pakistani students in promoting democracy, freedom of expression and greater political awareness about their rights. 
Users enjoy utilizing social media platforms for entertainment and information sharing because social media platforms are very useful in spreading information rapidly to a large number of people (Noorriati et al., 2012, Park et al., 2014). Most often, in daily life, individuals are inclined towards using forums, social networks, microblogs or blogs, photo/video sites, and other platforms for purposes such as exchanging opinions, keeping in touch with friends, find entertainment, discover their surroundings, express themselves or even to network with work acquaintances and money making activities and so on (UM EMEA research team, 2012). Social media platforms offer a variety of information and resources to help people to find, obtain, and share information, find entertainment or maintain contact with others.

Using social media, people can now get a great deal of direct and up-to-date information. A study by Pettigrew et al (2002) showed that online activities are affected by social media, and that this media have altered people's information seeking habits. The study showed that people have started using social media for a variety of information needs, such as breaking news, commerce and business, online references such as dictionaries, socialization, or making travel plans, as well as shopping, searching for medical information and advice. Social media fulfil so many functions in people's lives in a timely and convenient way (UM EMEA, 2012, Pettigrew et al., 2002). Furthermore, it can provide a great deal of help because they are interactive and involve communication both ways. For this reason, people can find information related to their own particular problems (Savolainen, 1998). The driving reasons for adoption of social media are the functionality, progressively ubiquitous access flexibility, and convenience of social technologies (Schroeder, Minocha, \& Schneider, 2010)

From the perspective of Uses and Gratifications (U\&G) theory, audiences are considered active and goal-directed and intend to achieve those goals through specific media content and communication platforms (Armstrong \& McAdams, 2009; Rubin \& Perse, 1987). Social media platforms are be likely to be repositories for sports, weather, news, entertainment, retail advertising, commentaries, and so on.

As opposed to traditional media, social media provides users with a wider variety of media contents and options. In mass communication studies, U\&G theory, is considered one of the best models for studying the users' underlying motives for media use (LaRose \& Eastin, 2004) and many researchers have used it. For example, this theory was used to explore factors that contributed to a content-generation online community in the study by Lampe et al (2010), and showed that various reasons are connected to different users. Furthermore, studies on the reasons for using various computer-mediated communication (CMC) technologies show that there are a number of needs being gratified, such as friendship, warmth, leisure, entertainment, fashion, and others (Leung, 2001); trendiness, amusement, information seeking, relationship maintenance, and wasting time $(\mathrm{Ku}, \mathrm{Chu} \& \mathrm{Tseng}$, 2013; Lo \& Leung, 2009).

The above-mentioned studies were concerned with the reasons and requirements of the media users. If we take reading the news as an example, people are thought to engage in active selection from among news sources to satisfy their different news needs, such as entertainment, information skimming, interpersonal communication and information scanning (Lin, Michael \& Rasha, 2005); information seeking/surveillance, socialization and entertainment (LaRose, 2006). However, with students trend towards greater sharing in social media, as shown in a study in Singapore reveals that their behaviour is motivated by status seeking, socializing and information seeking (Lee and Ma, 2011). However, the most important reason why people consume the news is to obtain information. 


\section{METHOD}

Research used focus group discussion (FGD) which involved two different levels of groups, both postgraduate and undergraduate students' groups had six participants. The participants are been selected from are UM students, as well as exchange students, from overseas, by using convenience sampling. The main library became the main place to find FGD participants. They will be asked whether they are willing to participate in this research or not. After they agreed, their contact number were taken to arrange the date, time and venue for the discussion.

This FGD was conducted in effort to know whether there would be different social media usage in ELIS due to level of study between these two groups. Focus Group Discussion (FGD) was conducted on March 10, 2014. The postgraduates' group discussion was conducted in the morning while the group of undergraduate students was at night. Both discussions are conducted near the main library and each discussion takes approximately 60 to 90 minutes. Both discussions were audio recorded with the participants' permission. Then it was transcribed, and shown to the participants for a member-check (i.e. participants verify the accuracy of the transcription based on what they remember of the FGD).

\section{FINDINGS}

FGD has been done and 12 students involved in this discussion as shown in Table 1:

\section{Table 1: Focus Group Participants}

\begin{tabular}{ccc} 
Postgraduate & Nationality & Discipline/are of study \\
PG1 & China & Media Studies \\
PG2 & Iran & English as Second Language \\
PG3 & China & English as Second Language \\
PG4 & China & Analytical Chemistry \\
PG5 & Iran & Media Studies \\
PG6 & Iran & Quantum Physics \\
Undergraduate & Nationality & Discipline/are of study \\
UG1 & China & TESL \\
UG2 & China & Accounting \\
UG3 & China & Building Surveying \\
UG4 & China & TESL \\
UG5 & Yemen & Engineering \\
UG6 & China & Engineering \\
\hline
\end{tabular}




\section{Information Seeking Ways/Sources}

The 12 participants from the two groups of different levels of study all use social media, and the majority of them use social media every day. For the participants at the postgraduate level, four of them said that they prefer using the Internet for seeking information online. The other two prefers participants stated that they prefer talking face-to-face with friends. As for undergraduate students, all six participants usually prefer using online sources, sometimes from some websites; sometimes they use social media to acquire the information.

By comparing the top three most important information type for everyday-life use and the social media platforms used, the three types of information that were mentioned most frequently in the graduate group are information about homes and families, academic and news/current affairs. The other three types of information mentioned most frequently by the undergraduate students group are news/current affairs, self-improvement and information about friends for socializing.

\section{Table 2: Important Information for Postgraduate Students}

\begin{tabular}{|c|c|c|c|}
\hline & $\begin{array}{l}\text { Top } 3 \text { important } \\
\text { information }\end{array}$ & $\begin{array}{l}\text { Social media } \\
\text { platforms }\end{array}$ & $\begin{array}{l}\text { Other } \\
\text { Sources }\end{array}$ \\
\hline \multirow[t]{3}{*}{1} & Home \& families & SNS(QQ, WeChat) & Skype \\
\hline & Academic & & $\begin{array}{l}\text { Library, Professional research paper } \\
\text { websites }\end{array}$ \\
\hline & Fashion & & Online magazines, newspaper \\
\hline \multirow[t]{3}{*}{2} & Self-improvement & & Printed/ online books \\
\hline & Academic & YouTube & Professional research paper websites \\
\hline & Health & & Call families \\
\hline \multirow[t]{3}{*}{3} & Chinese news & Message boards & \\
\hline & Research articles & & $\begin{array}{l}\text { Library, } \\
\text { online books, Professional research paper } \\
\text { websites }\end{array}$ \\
\hline & Friends & SNS(QQ, WeChat) & Calls \\
\hline \multirow[t]{3}{*}{4} & Sports & $\begin{array}{l}\text { Message boards } \\
\text { (Netease mobile app) }\end{array}$ & Sina news \\
\hline & Jobs & Forums & \\
\hline & Sales & & AirAsia website, Mudah.my \\
\hline \multirow[t]{3}{*}{5} & News/ current affairs & & Khabar online, $C N N, B B C$ \\
\hline & Friends & Facebook, WhatsApp & Skype, Viber, calls \\
\hline & Home \& families & Facebook & Skype, Viber, calls \\
\hline \multirow[t]{3}{*}{6} & Academic & Wikipedia & Professional research paper websites \\
\hline & Home \& families & & Calls \\
\hline & Home country news & & Yahoo! News, $B B C, C N N$ \\
\hline
\end{tabular}


Table 3: Important Information for Undergraduate Students

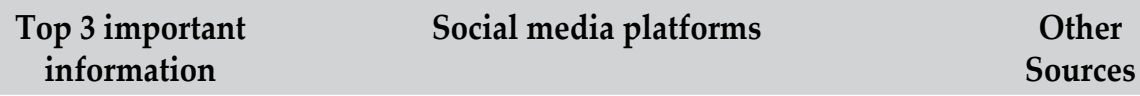

1 News/ current affairs Message boards (Today's top news)

Vocabularies

(academic)

Mobile dictionary app

Friends and other people SNS(WeChat)

\begin{tabular}{lll}
\hline Latest finance \& economics & SNS(WeChat) & Bloomberg.com \\
information (news)
\end{tabular}

Academic information

Library, human sources,

Self-improvement (CFA, ACCA)

Video sharing (YouTube, Xunlei) Newspapers, books, movie

3 Fashion Facebook

Weather

Yahoo! Weather

News of entertainment

circle (leisure)

Online websites(eonline.com)

\begin{tabular}{|c|c|c|c|}
\hline \multirow[t]{3}{*}{4} & Latest news & $\begin{array}{l}\text { SNS (WeChat, Facebook) Microblog } \\
\text { (SinaWeibo) }\end{array}$ & \\
\hline & $\begin{array}{l}\text { K-pop news } \\
\text { (leisure) }\end{array}$ & $\begin{array}{l}\text { Microblog } \\
\text { (SinaWeibo) SNS(Facebook) }\end{array}$ & \\
\hline & Friends & $\begin{array}{l}\text { SNS(Facebook) } \\
\text { Microblog } \\
\text { (SinaWeibo) }\end{array}$ & \\
\hline \multirow[t]{3}{*}{5} & Work \& study & YouTube & \\
\hline & Self-improvement & & Audio-books, Shareslide.com \\
\hline & Leisure & YouTube, Facebook & \\
\hline \multirow[t]{3}{*}{6} & Transportation & & Human source, online map \\
\hline & News of Malaysia & Facebook & Yahoo! News \\
\hline & Food & & Human source \\
\hline
\end{tabular}

Seeking academic information seems like a common information-seeking practice among four postgraduate students. It is usually sought by using library sources, Google Books and online database, such as EBSCO and web of science. Besides these sources, two of the participants (PG2, PG6) use YouTube and Wikipedia as their channels to get academic information as well. YouTube is treated as a useful source which provides professional academic knowledge by attracting institutions of higher learning to release their courses:

I think YouTube can be reliable for academic. Because nowadays many universities have their YouTube channels, like Princeton, University of Denver. So it's part of the 
university education. It can be remote courses. And MIT always has courses online, and it is free for everyone. That's part of their policy. But I pursue academic journals also. When you read, you also learn from the journals. But if there is something specifically you want to know, it is hard to go because there is something like skills, like writing skills, or presentation skills, so I turn to online sources, YouTube.

For home and family information, social media platforms, and other sources show the same usage opportunities and functions in acquiring information. Two students (PG1, PG5) use SNS (Facebook, QQ, WeChat), Internet-based instant messenger (Skype, Viber) and normal calls to know the latest information from home and their families. In addition to those channels, the normal calling is mainly used by PG3 and PG6 who need to know how their families are. SNS shows advantages in seeking information, the instant sending across time and area restrictions and the prevalence makes students inclined to use them.

Both social media and other sources are used for seeking information about sports and friends. In addition to using the Sina news website, the mobile applications of news provide the latest news of sports, short videos of basketball matches and easy access is the reason that the student (PG4) chooses this kind of applications. SNS shows the advantages of instant message and popularity for acquiring latest friends' news and contact with them.

I use QQ and WeChat to know how my hometown friends are, because most of my friends use that. It is easy and convenient to reach them, and I can check their space to know what is going on with them and share some news with them. The message is instantly sent to them. But if I want to contact my friends here, in Malaysia, just call them or send them message, which is easier."

When I wake up, the first thing for me is the open my Facebook every morning. I can check what is going on with my friends, where they went. I can check the photos and their notes so that I can give my comments there to give my ideas to them.

Findings from the FGD indicate that social media sources are not playing a very important role in seeking information about self-improvement, health, and fashion. Printed or e-books are perceived as the more useful source to improve oneself and when faced with health problems, PG2 usually calls the family to consult and ask their opinions and advice on how to live a healthier life. PG1 who seeks fashion information, usually reads online magazines or newspapers, or just gets the information by browsing the advertisements displayed on the websites. In fact, the online forums are a better choice for PG4 who seeks information related to job opportunities. He usually acquires the latest recruitment/vacancy information or the qualifications by browsing and posting in online forums, such as 0060 and Xiao $\mathrm{Mu}$ Chong (Chinese forum).

It can be seen that members of both groups think that news/current affairs is very important information. However, postgraduates focus more on academic information, and show their consideration and affection for their families as said by PG5. 
I am very concerned [about] my families. You know my parents are not young any more, and now I am in Malaysia, I need to know how are they. For my siblings, I check the status and pictures and I know where she went, and how is everything going with her.

On the other hand, undergraduate students focus more on self-improvement and development. They are active in creating and maintaining good relationships with others.

For keeping relationship with each other, including families and friends. In Malaysia, we Muslims have our own Muslim association, and I have to connect some brothers and sisters from the Chinese Muslim Association. Sometimes, we use Facebook group and talk there.

I "explore others' life" of my friends. I'd like to check the various news about my friends to know the latest information about them. For my local friends, they are all very interested in their social life, like Facebook, so I can find them as soon as possible Facebook.

Findings from the FGD indicate that social media sources are not playing a very important role among students in seeking information about self-improvement, health, and fashion. Printed or e-books are perceived as the most useful source to improve oneself and when faced with health problems, PG2 usually calls the family to consult and ask their opinions and advice on how to live a healthier life. PG1 who seeks fashion information, usually reads online magazines or newspapers, or just gets the information by browsing the advertisements displayed on the websites. In fact, the online forums are a better choice for PG4 who seeks information related to job opportunities. He usually acquires the latest recruitment/vacancy information or the qualifications by browsing and posting in online forums, like 0060 and Xiao Mu Chong (Chinese forum).

For the social media platforms' usage in their ELIS, there are obvious differences in usage between both groups. Despite the fact that both groups use social media platforms to seek information, the undergraduate students use more social media platforms for seeking everyday-life information. Besides that, undergraduate students also use SNS more frequently than postgraduate students as well. Sina blog and the microblog Weibo, SNS (WeChat, QQ, and Facebook), YouTube, and Wikipedia are the social media platforms that 12 international students use the most or find most useful.

\section{Types and Reasons of Social Media Platforms Used}

Based on the identified news gratifications (LaRose, 2006) and four principal needs for joining a Facebook group (Park et al., 2009), and the feedback of the information that is sought by social media, the six main needs expressed by the 12 international students during the FGD are information, socializing, affection needs, cognitive needs, self-seeking, and entertainment. For postgraduate students, their seeking information more for their academic purposes. Based on FGD, some said they use YouTube and Wikipedia. Since most of this group members need 
to do research, they are not relying on social media solely. They also use another platform or source such as a library, Google Books and online database as stated below:

... While when I use YouTube to learn, it is easy to help me find the professional video from the top ranked university.

Usually I search articles or papers related to my research from Elsevier. When I need to know some items' general knowledge, I will go to Wikipedia, where I can find various explanations.

Information seeking also is used for learning, exploring, discovering and understanding the world. In addition, seeking information about the local food is also a way to explore the world around oneself and meet the basic information needs for life.

You know, we are very far away from home, I really need to know what is happening in China. And when I use kind of Netease mobile news app, it post the latest news, like economics, top news, health or cars, like everything and it keeps updating. At the same time, I can check the news or topic that I subscribed and that I am interested in.

I need to keep myself fresh about the world. So I need news, which can either be international, or news from my own country which is China.

Usually I am used searching all kinds of news, no matter it is current affairs, or specific sports, economics, entertainment.

Funny things always relax me. So I subscribed some funny pages on Facebook, and if I like the content, I will share with my friends to enjoy it.

Now we are in Malaysia, so I think it is important to know the news in Malaysia.

Seeking friends' latest status and information are motivated by international students' socializing needs. They need to get the news from their acquaintances to connect with and keep in touch with them. For international students here, maintaining relationships with both old friends of home country and new friends here is quite necessary.

I usually check my friends' news to know about them, because my Chinese friends and I are now in different places, even in different countries. By using WeChat and $\mathrm{QQ}$, it is convenient for me to contact them and check the latest news because most of my friends use that two applications. And the message can be sent to me instantly and I can check their space or latest status as soon as possible. 
Facebook and I can know what do they post, what kinds of idea and opinion of them and I can give my comments.

For keeping relationship with each other, including families and friends. In Malaysia, we Muslims have our own Muslim association, and I have to connect some brothers and sisters from the Chinese Muslim Association. Sometimes, we use Facebook group and talk there.

I "explore others' life" of my friends. I'd like to check the various news about my friends to know the latest information of them. For my local friends, they are all very interested in their social life, like Facebook, so I can find them as soon as possible by Facebook.

Affection needs motivate the students to seek the latest information about their homes and families. International students are far away from home, they need to know about their families, and get psychological communication and support by keeping in touch with them. Although the information seeking of friends can reflect the participants' socializing needs, their affection needs can be fulfilled from their seeking and communicating with close friends as well.

I need to know about my parents' health and the latest news about my relatives. I want to know how they are doing because they are families. Sometimes when I come across something or some difficulties, by using WeChat and QQ, I can easily get the suggestions and courage from my families.

I am very concerned my families. You know my parents are not young any more, and now I am in Malaysia, I need to know how are they. For my siblings, I check the status and pictures and I know where she went, and how is everything going with her.

Sometimes I will check the space to know what she/he is doing recently, and I can see the pictures of them.

The fifth self-seeking need for students is the need for self-improvement. No matter the personal taste or positive energy guide or future development, students are always trying to know themselves better to improve and become better persons with a brighter future. One way they do so is by seeking information about jobs and fashion.

I am a full research student and also a research assistant. Actually I think if I can raise the standard of myself, I think I am able to do every kind of jobs, not only in the research field. When I search the related job or recruitment information in the forums, I know the qualification required, and I can improve myself according to 
the ideal job request from language or other certificates obtained by exam later. I think all the effort are for jobs, it can afford $u$ a more stable life income.

In fact, I think it is easy to get the fashion things. Fashion can improve my taste and know the current fashion trend.

Seeking information about sports and K-pop news fulfils the students' entertainment needs. Life for international students is not only academic. They have their hobbies and their own ways to relax.

I love sports, so I usually search every kind of sports news, special basketball. I like to watch NBA's matches, or some short videos. Also, I am concerned of Liu Xiang. I want to know whether he can stand up or not to be back to the competition.

(PG4)

I am interested in K-pop news. Because it is too hot and updated so fast, as a trend follower, you have to keep yourself fresh.

In fact, the information seeking findings mentioned above show that the students' six main needs are fulfilled by their process of seeking and acquiring everyday-life information. They use various social media platform such as SNS (e.g. WeChat, QQ, and Facebook), video sharing sites (e.g. YouTube), microblogs (e.g. SinaWeibo), collaborative project sites (e.g. Wikipedia) and message boards (e.g. mobile news' applications) to acquire the information they need for everyday life and the information results sought by social media they perceive are useful for them. The 12 international students think that the information sought by social media is useful for them and gratifying for different usages.

They are more gratified with the SNS and video sharing sites for fulfilling their needs. For instance, YouTube for academic information: the students think knowledge is very valuable and is something they need to pay for and hard to get sometimes. However, the academic sources provided by social media are a great privilege, because they are free now. Many people are doing a lot of effort to keep the knowledge presented online easily accessible to ordinary people and the knowledge that is habitually sought after is usually uploaded by reputable universities.

As an aspect of detail SNS utilization in ELIS, these international students utilized SNS not only to contact and get news from home and families, or maintaining friendship, but to get the academic and the self-improvement message and the latest news no matter for caring or knowing about the world or leisure as well from the frequency mentioned. It shows that SNS' high utilization in UM international students' ELIS is not mainly because of its social capital cultivation, the information source function is increasingly becoming more important to international students as well. The attitudes and reflection of the SNS show its gratification as being information sources. 


\section{Usefulness of Social Media Plafforms}

All the participants stated that the information obtained by using social media platforms is useful for them. Some of information useful to maintain a relationship with their family and friends as stated by most of participants in postgraduate group such as PG1, PG3 and PG5. Information about the families and friends sought by social media became a platform for showing affection. It connects people across time zones and area restrictions, so whenever and wherever students are, they can use this media to obtain the latest information about subjects or people that concern them.

I think it is convenient for all the Chinese and we use QQ when we were little children. Chinese children also have their own QQ and have their own friends' circle, like this. So we just talk with each other with QQ, and I think the most important thing I use QQ is very convenient.

(PG1)

I usually check my friends' news to know about them, because my Chinese friends and I are now in a different place, different countries. By using WeChat and QQ, it is convenient for me to contact them and check the latest news because most of my friends use that two applications. And the message can be sent to me instantly and I can check their space or latest status as soon as possible.

(PG3)

I usually open Facebook to check my friends' news. Because most of them use Facebook and I can know what do they post, what kinds of idea and opinion of them and I can give my comments.

Since this media is free, it useful to get latest information on their hobbies or interesting subject that can be shared with other people, including friends. They can subscribe to the news, blogs or homepage they are interested in, as well as get news about politics, technologies, or famous people or even special subjects quickly and to fulfil their needs. It can provide personalized content. Furthermore, social media can help seek the information very fast and easily. They save much more time and energy. The selected social media platforms are prevalent and popular. Therefore, it is easy and convenient to access the latest information or to reach someone.

In fact, I think it is easy to get the fashion things as reference. Fashion can improve my taste and know the current fashion trend.

Funny things always relax me. So I subscribed some funny pages on Facebook, and if I like the content, I will share to my friends to enjoy it.

It's free. WeChat is free. And then, second one is because it's important to use, you can easily can open it, and talk to your friend. 
Besides that, as students, this media also useful for background information needs, and reflecting the latest real information which is not necessary to evaluate the truth. Therefore, it provides more comprehensive information, it fulfils students' needs for general understanding, and of course more professional and reliable knowledge or information related to academic or professional work.

Because I am majoring in accounting, so I am used to be more concern the latest information of finance and economics. I use WeChat, because there is official account. Everyday release is very useful. This is the accounting certificate.

When I search for the journals for my study, I need to look at the category whether there is tier 1, tier 2, tier 3 clearly organized to check whether the knowledge is sloppy or solid. Sometimes the journal you found is not reliable. While when I use YouTube to learn, it is easy to help me find the professional video from the top ranked university. YouTube is really useful for me.

From the aspect of U\&G theory, it is obvious that international students' main information needs get fulfilled and gratified during the process of using social media for information seeking. Therefore, the particular social media platforms provide useful information from their point of view. Data from FGD indicate the advantages and potential in the usage of social media in ELIS for international students, and explain the reasons that attract them to use social media for information seeking and that social media have the capability to provide the perceived useful information for international students to fulfil the needs of daily life. It shows the huge potential of social media platforms in international students' ELIS.

\section{DISCUSSION AND CONCLUSION}

In this study, some of the findings are similar with the existing research. First, findings about the specific SNS usage and SNS popularity are similar to many studies where SNS was found to be the most frequently used social media among students and social media show their potential utilization among university students (Liu, 2010; Garrett \& Cutting, 2012; Hussain, 2012). Second, as for the influence of the level of study, the FGD shows that undergraduate students use SNS more frequently. This is in line with studies by Sin and Kim (2013) and Maden and Zickuhr (2011). Third, Wikipedia and YouTube are used for academic purposes. The findings show that Wikipedia and YouTube have several advantages in obtaining various types of academic and visual knowledge for learning, which is similar to the data from some empirical studies (Head \& Eisenberg, 2009; Talug, 2012). Fourth, students use SNS most frequently, to fulfil specific needs, such as information, socializing, affection needs, cognitive needs, self-seeking and entertainment. These motivations to use social media represent the main reasons for students' use for of SNS to gratify their needs, which is similar to findings of previous researchers about joining and using Facebook.

Although the findings share some similar results with empirical data, the study has its own significant meanings. This research examined the everyday-life information needs of international students in Malaysia. It is different to the results of Sin and Kim (2013) where the financial information was the most important, and housing ranked in the top five in the 
view of international students studying in the U.S. The other three top-five information types were health, news of one's home country and entertainment. So far, this is the only directly comparable study on the different everyday information needs of international students. It is possibly reflected in the different needs of two countries where the different environment is a factor that may influence the information seeking and information needs.

One finding shows that specific social media platforms are utilized in ELIS. Some studies found that university students usually use various social media tools or channels in particular ELIS (Lin, 2002) and "search engines" are mainly the first choice to seek academic and everyday-life information as well (Korobilil et al., 2011; Malliari et al., 2011). As for international students' fifteen types of ELIS, the findings provide the specific and most preferable social media platforms, such as SNS, social reviews, bookmarking sites and video sharing are used for everyday-life information seeking needs. Certainly, it is a little different from prior studies in that it suggests possible relationships between the types of information needs and the choice of requested information sources (Barrett, 2005; Callinan, 2005; Cosijn, 2006; Davies, 2007) which focus more on academic study and other types of information needs. This study concentrates on everyday-life information needs; therefore, the results actually reflect the choices of different information types in ELIS, which are more centralized within those four social media platforms. With regard to preferable usages of social media in ELIS, this is an important, comprehensive and specific finding for social media managers to take into account when planning or adjusting in the future to align their services with students' patterns and habits. In addition to that, the findings of the information seeking strategies can contribute to a smoother cross-cultural transition and adaptation to the new host country for international students particularly for students in Malaysia.

Overall, this studies shows thet social media platforms are the popular and useful channels for UM international students for acquiring the information they need for everydaylife use. The study shows that social media platforms, particularly SNS, play a very important role in information seeking for UM international students who are currently living and studying in Malaysia.

\section{REFERENCES}

Agosto, D. E., \& Hughes-Hassell, S. (2005). People, places, and questions: an investigation of the everyday life information-seeking behaviors of urban young adults. Library and Information Science Research, 27, 141-163

Armstrong, C., \& McAdams, M. (2009). Blogs of information: how gender cues and individual motivations influence perceptions of credibility. Journal of Computer Mediated Communication, 14(3), 435-456.

Barrett, A. (2005). The information-seeking habits of graduate student researchers in the humanities. Journal of Academic Librarianship, 31(4), 324-331.

Bauer, T. N. et al. (2007). Newcomer adjustment during organizational socialization: a metaanalytic review of antecedents, outcomes, and methods. Journal of Applied Psychology, 92(3), 707-721

Callinan, J. E. (2005). Information-seeking behavior of undergraduate biology students. Library Review, 54(2), 86-99. 
Carpan, C. (2010). Introducing information literacy 2.0. College $\mathcal{E}$ Undergraduate Libraries, 17(1), 106-13.

Chen, C. P. (1999). Common stressors among international college students: research and counselling implications. Journal of College Counseling, 2(1), 49-66.

Cheng, K.H., Liang, J.C., \& Tsai, C.C. (2013). University students' online academic help seeking: the role of self-regulation and information commitments. The Internet and Higher Education, 16, 70-77.

Cosijn, E. (2006). Relevance judgments within the context of work tasks. In Ruthven, I., Borlund, P., Ingwersen, P., Belkin, N. J., Tombros, A. \& Vakkari, P. (Eds.). Proceedings of the International Conference on Information Interaction in Context (pp. 20-29). Copenhagen, Denmark: ACM.

Cox, D.M. et al. (2005). Working with students with difficulties: academic and nonacademic. In Ruth-Marie E. Fincher (Eds.), Guidebook for Clerkship Directors (3rd ed.) Retrieved from http://familymed.uthscsa.edu/ACE/guidebook.htm

Davies, K. (2007). The information-seeking behaviour of doctors: a review of the evidence. Health Information \& Libraries Journal, 24(2), 78-94.

Garrett, B. M., \& Cutting, R. (2012). Using social media to promote international student partnerships. Nurse Educ Pract, 12(6), 340-345.

Giannakos, M. et al. (2012). Using Facebook out of habit. Behaviour and information technology. New York: Taylor and Francis Group.

Given, L. M. (2002). The academic and the everyday: investigating the overlap in mature undergraduates' information-seeking behaviors. Library and Information Science Research, 24, 17-29.

Hyun, J., Quinn, B., Madon, T., \& Lustig, S. (2007). Mental health need, awareness, and use of counseling services among international graduate students. Journal of American College Health, 56(2), 109-119.

Jeong, W., (2004). Unbreakable ethnic bonds: information-seeking behavior of Korean graduate students in the united states. Library E Information Science Research, 26, 384-400.

Head, A. J., \& Eisenberg, M. B. (2011). How college students use the web to conduct everyday life research. First Monday, 16(4).

Hussain. I. (2005). A study of emerging technologies and their impact on teaching learning process; An unpublished PhD Dissertation, Allama Iqbal Open University Islamabad.

Hwang, Y., \& Shim, H., (2010).Opinion leadership on Twitter and Twitter use. Journal of Korean Broadcasting, 24(6), 365-404.

Java, A., et al. (2007). Why we Twitter: understanding microblogging usage and communities. Proceedings from: the Joint 9th WEBKDD and 1st SNA-KDD Workshop (pp. 56-65)

Jones, S., Johnson-Yale, C., Millermaier, S. \& Pérez, F. S. (2009). Everyday life, online: U.S. college students' use of the Internet. First Monday, 14(10), from http://firstmonday.org/ htbin/cgiwrap/bin/ojs/index.php/fm/article/view/2649/2301

Kim, Kyung-Sun, Sei-Ching Joanna Sin, and EunYoung Yoo-Lee. "Undergraduates' use of social media as information sources." College \& Research Libraries (2013): crl13-455.

Kim, K.S., Lee, E. Y. Y., \& Sin, Sei-C. J. (2012). Social media as information source: undergraduates' use and evaluation behavior. Proceedings from the ASIST Annual Meeting 48 (2011). 
Korobili, S., et al (2006). Factors That Influence the Use of Library Resources by Faculty Members, Library Review, 55, 91-105.

Lampe, C., Wash, R., Velasquez, A., \& Ozkaya, E. (2010). Motivations to participate in online communities. Proceedings from the International Conference on Human Factors in Computing Systems (pp. 1927-1936). New York: ACM

LaRose, R. (2006). Getting hooked on news: uses and gratifications and the formation of news habits among college students in an Internet environment. Journal of Broadcasting E Electronic Media, 50(2), 93-210.

Lee, C. S., \& Ma, L. (2012). News sharing in social media: the effect of gratifications and prior experience. Computers in Human Behavior, 28(2): 331-339.

Leung, L. (2001). College student motives for chatting on ICQ. New Media and Society, 3(4), 483-500

Lin, C. A. (2002). Perceived gratifications of online media service use among potential users. Telematics and Informatics, 19.

Lin, C., Michael, S., \& Rasha, A. (2005). Uses and gratifications of online and offline news: new wine in an old bottle? In S. Michael, B. Garrison, \& D. Mahwah (Eds.). Online news and the public. Mahwah, NJ: Lawrence Erlbaum

Lin, J. C. G., \& Yi, J. K. (1997). Asian international students' adjustment: issues and program suggestions. College Student Journal, 31(4), 473-479.

Liao, Y., Finn, M., \& Lu, J. (2007). Information-seeking behavior of International graduate students vs. American graduate students: a user study at Virginia Tech 2005. College and Research Libraries, 68, 5-25

Liu, M. X., \& Redfern, B. (1997). Information-seeking behavior of multicultural students: a case study at San Jose State University. College and Research Libraries, 58, 348-354.

Liu Y. (2010). Social media tools as a learning resource. Journal of Educational Technology Development and Exchange, 3(1), 101-114.

Malaysia has one of the highest proportions of international students pursuing higher education. (2015, January 29). The Sun Daily.

Madden, M., \& Zickuhr, K. (2011). 65\% of online adults use social networking sites. Washington, DC: Pew Internet \& American Life Project. Retrieved from http://www. pewInternet.org/2011/08/26/65-of-online-adults-use-social-networking-sites-2/

Madden, M \& Jones, S. (2002). The Internet goes to college. Pew Internet \& American Life Project, from http://www.pewinternet.org/Reports/2002/The-Internet-Goes-to-College. aspx

Malliari, A., et al. (2011). Exploring the information seeking behavior of Greek graduate students: a case study set in the University of Macedonia. The International Information E Library Review 43(2), 79-91.

Maqsood Ahmad Shaheen (2008). Use of social networks and information seeking behavior of students during political crises in Pakistan: a case study. The International Information E Library Review, 40(3), 142-147.

Marchionini, G. (1997). Information Seeking in Electronic Environments. New York: Cambridge University Press.

Mitchell, A., et al. (2013). The role of news on Facebook. PewResearch Journalism Project. Retrieved from http://www.journalism.org/2013/10/24/the-role-of-news-on-facebook/ 
Mischaud, E. (2007). Twitter: expressions of the whole self. MSC dissertation, London: School of Economics and Political Science.

Noorriati Din, Sadiah Yahya, Raja Suzan, \& Raja Kassim. (2012). Online social networking for quality of life. Procedia - Social and Behavioral Sciences, 35, 713-718.

Mori, S. (2000). Addressing the mental health concerns of international students. Journal of Counseling and Development, 78, 137-144.

Park, N., Kee, K. F., \& Valenzuela, S. (2009). Being immersed in social networking environment: Facebook groups, uses and gratifications, and social outcomes. CyberPsychology and Behavior, 12, 729-733.

Park, C. S. (2013). Does Twitter motivate involvement in politics? Tweeting, Opinion leadership, and political engagement. Computers in Human Behavior, 29(4), 1641-1648

Park, J. H. et al. (2014). An investigation of information sharing and seeking behaviors in online investment communities. Computers in Human Behavior, 31, 1-12

Pettigrew, K.E. (2000). Lay information provision in community settings: how community health nurses disseminate human services information to the elderly. The Library Quarterly, 70(1), 47-85

Poyrazli, S., \& Grahame, K. M. (2007). Barriers to adjustment: needs of international students within a semiurban campus community. Journal of Instructional Psychology, 34(1), 28-46

Savolainen, R. (2008). Source preferences in the context of seeking problem-specific information. Information Processing \& Management, 44(1), 274-293

Schroeder, A., Minocha, S \& Schneider, C. (2010). Social software in higher education: The diversity of applications and their contributions to students' learning experiences. Communications of the Association for Information Systems, 26, 547-564

Shoham, S., \& Strauss, S. K. (2008). Immigrants' information needs: their role in the absorption process. Information Research, 13(4)

Sin, Sei-C. J., et al (2011). International students' aculturation information seeking: personality, information needs and uses. Proceedings of the American Society for Information Science and Technology. 48 (1), 1-4.

Sin, Sei-C. J., \& Kim, Kyung-S., (2013). International students' everyday life information seeking: the informational value of social networking sites. Library $\mathcal{E}$ Information Science Research, 35(2), 107-116

Smith, R. A., \& Khawaja, N. G. (2011). A review of the acculturation experiences of international students. International Journal of Intercultural Relations, 35, 699-713

Talug, D. Y. (2012). Lifelong learning through out today's occasions namely social media and online games. Procedia - Social and Behavioral Sciences, 46, 4431-4435

Tseng, W. C., \& Newton, F. B. (2002). International students' strategies for well-being. College Student Journal, 36(4), 591-597.

UM EMEA research team (2012). The business of social. Social media tracker 2012. NY: UM

Ward, C. (2001). The A, B, Cs of acculturation. In D. Matsumoto (Ed.). The Handbook of Culture and Psychology (pp. 411-446). Oxford: Oxford University Press

Ward, C., Leong, C-H., \& Kennedy, A. (1998). Self construals, stress, coping and adjustment during cross-cultural transition. Annual Conference of The Society of Australasian Social Psychologists, Christchurch, New Zealand 
Warner, E. S., Murray, A. D., \& Palmour, V. E. (1973). Information needs of urban residents. Washington. DC: US Department of Health, Education, and Welfare. Office of Education, Bureau of Libraries and Learning Resources

Wilson, T. D. (2006). On user studies and information needs. Journal of Documentation, 62(6), 658-670.

Whiting, A. \& Williams, D. (2013). Why people use social media: a uses and gratifications approach. Qualitative Market Research: An International Journal, 16(4), 362-369.

Yi, Z. (2007). International student perceptions of information needs and use. Journal of Academic of Librarianship, 33, 666-673.

Zhao, D., \& Rosson, M.B. (2009). How and why people twitter: the role that micro- blogging plays in informal communication at work. Proceedings ACM 2009 International Conference on Supporting Group Work.

Zickuhr, K. (2010). Generations 2010. Pew Internet \& American Life Project, from http:// www.pewinternet.org/ /media//Files/Reports/2010/PIP_Generations_and_Tech10.pdf,

Zuria Mahmud, Salleh Amat, Saemah Rahman, \& Noriah Ishak. (2010). Challenges for international students in Malaysia: culture, climate and care. Procedia - Social and Behavioral Sciences, 7, 289-293 